\title{
A avaliação do impacto da Companhia Integrada de Polícia de Proximidade (CIPP)
}

\author{
Bruno Ottoni Eloy Vaz* \\ Emmanuel Antonio Rapizo Magalhães Caldas ${ }^{* *}$
}

\begin{abstract}
Resumo
Este trabalho apresenta uma avaliação de impacto da implementação da Companhia Integrada de Polícia de Proximidade (CIPP), projeto realizado pela Polícia Militar do Estado do Rio de Janeiro (PMERJ). Utilizando o método de controle sintético e dados do Instituto de Segurança Pública do Rio de Janeiro (ISP), encontra-se que a CIPP implica em uma redução de crimes comparativamente ao grupo de controle. Porém, nota-se que a redução dos crimes decorrentes da implementação da CIPP não é estatisticamente diferente daquela observada em áreas que ficaram fora do programa.
\end{abstract}

Palavras-chave: crime, polícia, segurança pública

JEL: K42,O38, O54

\section{Introdução}

Nos últimos anos novas formas de serviços policiais têm sido aplicadas em todo mundo, objetivando superar dilemas e problemas presentes nos modelos tradicionais, voltados para a repressão, o controle urbano e a ostensividade policial. O policiamento comunitário, especialmente aquele desenvolvido no Japão e, posteriormente, nos Estados Unidos, tornou-se exemplo para as experiências latino-americanas das últimas décadas.

O dilema principal do modelo mais comum no século XX é que ele só pôde ser desenvolvido com o avanço tecnológico e à custa do distanciamento das comunidades. A criação das viaturas e rádios patrulhas, junto com as centrais de comunicação, permitiu que se policiassem mais lugares e mais rapidamente. Ao receberem notícias de crimes mais celeremente, as instituições aos poucos reduziram os contingentes dispostos nos bairros e comunidades para priorizar o atendimento veloz das demandas, afastando-se, assim, do cotidiano comunitário (Rolim, 2006: p. 29-30).

\footnotetext{
*Pesquisador do IDados. e-mail: bruno_ottoni@idados.org.br

**Especialista em políticas públicas e gestão governamental do Instituto de Segurança Pública (ISP) e doutorando em ciência política pelo Instituto de Estudos Sociais e Políticos da Universidade Estadual do Rio de Janeiro (IESP-UERJ). E-mail: emcaldas@gmail.com
} 
Nesse modelo de policiamento ostensivo, os policiais circulam com carros ou a pé pelas ruas e/ou se posicionam em sítios específicos. Ou seja, o policial se torna evidente e visível para sociedade e, especificamente, para os possíveis infratores. Em relação aos primeiros, espera-se que se sintam mais seguros, aos segundos, que considerem os riscos da prática de crimes como significativamente altos a ponto de desistirem. De maneira complementar, os policiais ficam atentos às chamadas de atendimento, buscando chegar o mais brevemente ao local do crime para interrompê-lo ou, ao menos, deter a fuga do infrator. A eficácia desse trabalho é medida pela rapidez da resposta e pela dissuasão de crimes pelo controle urbano (posicionando-se em locais estratégicos ou patrulhando ruas).

Esse tipo de prevenção é conhecido como situacional, e foca nas reduções de oportunidades, buscando interferir nos cálculos de custo-benefício daqueles interessados em praticar crimes. Essa estratégia, entretanto, é limitada, visto que atua somente na região com presença policial ${ }^{1}$. Estudos citados em Rolim (2006: 54-55), apontam que procedimentos relacionados exclusivamente ao atendimento de chamadas e patrulhas motorizadas são custosos e com baixa efetividade ${ }^{2}$, visto que atuam principalmente em crimes "já frios", ou seja, que ocorreram há tempo suficiente para diminuir significativamente as chances de encontrar o autor.

\section{2}

Devido a esta situação, torna-se cada vez mais comum a perspectiva de trabalho preventivo multidimensional, abarcando três níveis de ações, como sugerido pelo PNUD (2013). De maneira resumida tem-se que a prevenção, no nível primário, se centra nas condições objetivas, estruturais e institucionais para a prática do crime. Ou seja, nos fatores de riscos e situações de vulnerabilidade. No segundo nível está a prevenção situacional, na qual se baseia o policiamento tradicional, que atenta para os locais e momentos de ocorrência do crime. Por fim, a prevenção terciária busca impedir a reincidência criminal.

$\mathrm{O}$ que se tem nesse modelo é uma percepção mais integral da prevenção do crime, que se coaduna com o conceito de segurança cidadã. Esta é descrita pelo PNUD (2013) como uma ordem cidadã democrática que elimina as ameaças de violência na população e permite a convivência segura e pacífica. Tal concepção não dá enfoque exclusivo ao crime, focando-se mais nas ameaças à convivência. Dessa forma, as ações devem ser proativas e baseadas no estabelecimento de confiança e coesão social, e não somente no controle.

Compreendida dessa maneira, fica claro que o rol de práticas supera a capacidade das instituições policiais. A necessidade de políticas de diversos atores leva a construção de

\footnotetext{
${ }^{1}$ Como alguns autores citam (Waquim, 2009 e Rolim, 2006: 141), há dúvidas se a redução de crime nestes casos, em realidade, é efeito do deslocamento do mesmo para outras áreas. Outra crítica comum é a sustentabilidade dos efeitos positivos.

${ }^{2}$ Cita-se (Rolim. 2006: 42), por exemplo, que um patrulheiro a pé tem uma chance a cada 8 anos de trabalho de passar a menos de 30 metros de um assalto.
}

Econômica-Niterói, v. 19, n. 2, p. 87-110. dezembro, 2017 
uma ideia de segurança pública transversal. O policiamento de proximidade é um dos elementos dessa cadeia, e exige a participação de diversos atores societários em ações conjuntas para mitigar os riscos de violência. Os problemas comunitários são identificados, analisados e priorizados e as respostas, em princípio, são colocadas em prática de maneira integrada por todos aqueles atores governamentais e não governamentais capacitados.

É dentro dessa nova perspectiva que diversas experiências internacionais, como a do Modelo Nacional de Vigilância Comunitária por Quadrantes (MNVCC) da Colômbia e o Modelo Integrado de Polícia de Proximidade (MIPP) de Portugal, se inscrevem ${ }^{3}$. A própria Polícia Militar do Rio de Janeiro (PMERJ) já teve experiências de policiamento comunitário, como o Projeto Mutirão da Paz, o Grupamento de Policiamento em Áreas Especiais $(\mathrm{GPAE})^{4}$ e a atual Unidade de Polícia Pacificadora (UPP) ${ }^{5}$. Contudo, com a criação das Companhias Integradas de Polícia de Proximidade (CIPP), objeto do presente estudo, houve a primeira proposta de alteração da forma de organização e gerenciamento do serviço policial dentro dos batalhões da polícia militar, estruturando e sistematizando um novo modelo policial. Todos os projetos anteriores não afetavam a rotina operacional e gerencial do batalhão. As UPPs, até o final de 2017, por exemplo, possuíam comando e equipe administrativa própria.

Os objetivos da CIPP seriam a ampliação do contato com a população, e o aumento da legitimidade do mandato policial, impedindo que este se constitua basicamente pela autoridade. Esses parâmetros o aproximam da experiência das UPPs. O que está na base desse raciocínio é algo já expresso por alguns pesquisadores (Sherman e Tyler apud Rolim, 2006: 99): a legitimidade policial pode prevenir crimes. Justifica-se a atenção a CIPP, portanto, pelo objetivo desta de alterar o modelo padrão de gerenciamento da força policial dentro dos batalhões.

Assim, a PMERJ, ciente da necessidade de compreender os possíveis efeitos da CIPP, procurou realizar, juntamente com o Instituto de Segurança Pública (ISP), uma avaliação de impacto do seu projeto piloto, implementado na área da $20^{\mathrm{a}}$ delegacia de polícia (com sede em Vila Isabel). Este artigo apresenta, justamente, a avaliação de impacto deste projeto piloto. Mais precisamente, o presente estudo realiza uma avaliação quantitativa do efeito da implementação da primeira CIPP sobre o crime. Utilizando a metodologia de controle sintético, descrita detalhadamente em Abadie e Gadeazabal (2003) e revisitada em Abadie et al (2010), encontra-se que a implementação do projeto-piloto resultou em

\footnotetext{
${ }^{3}$ Esses projetos servem de modelo para a Companhia Integrada de Polícia de Proximidade (CIPP), foco do presente estudo, implementada pelo Estado do Rio de Janeiro. Para mais informações pode-se recorrer a FIP (2012) e PNC (2010), para o caso colombiano, e a Ferreira (2014) e Vasco (2014), para o caso português.

${ }^{4}$ Sobre o GPAE, ver Albernaz et al (2007).

${ }^{5}$ Muitos estudos foram realizados sobre as UPP. A partir de perspectivas distintas, os trabalhos a seguir dão um bom panorama sobre o assunto: Soares et al (2012), Borges et al (2012), Henriques e Ramos (2011) e Ottoni (2014).
} 
uma redução no número de crimes na área coberta pelo programa, comparativamente ao observado no grupo de controle. Porém, o efeito da primeira CIPP não chega a ser significativamente diferente daquele encontrado em áreas que não sofreram nenhum tipo de intervenção ${ }^{6}$.

Além desta introdução, o presente estudo está dividido em outras três seções. $\mathrm{Na}$ primeira, são descritos os objetivos, o território do tratamento e as atividades da CIPP. Na seção seguinte são apresentados os dados, a metodologia de controle sintético e os resultados da pesquisa. Por fim, há uma seção conclusiva.

\section{A Companhia Integrada de Polícia de Proximidade}

A Companhia Integrada de Polícia de Proximidade é um projeto da PMERJ, iniciado em 28 de fevereiro de 2015 nos bairros de Vila Isabel, Grajaú e Andaraí. Em termos operacionais, o projeto se baseia em três eixos principais: a divisão territorial com responsabilização operacional, o policiamento de proximidade e o policiamento orientado ao problema.

\subsection{A divisão territorial com responsabilização operacional}

Como dito anteriormente, o projeto piloto da CIPP foi instalado na área da $20^{\mathrm{a}}$ Delegacia de Polícia (DP), também conhecida como a Circunscrição Integrada de Segurança Pública (CISP) de mesma numeração ${ }^{7}$, que tem sede em Vila Isabel. A área de cobertura da referida delegacia compreende os bairros de Vila Isabel, Andaraí e Grajaú e está sob autoridade do $6^{\circ}$ Batalhão de Polícia Militar. Além disso, a $20^{\mathrm{a}}$ CISP possui quatro setores de policiamento, que recebem atenção detida de quatro equipes de rádio patrulha: Alpha, Bravo, Charlie e Delta. Esses quatro setores foram divididos em pequenos subsetores de policiamento de proximidade ${ }^{8}$, que em seu conjunto compõem a CIPP. São 11 subsetores no setor Alpha, 8 no Bravo, 9 no Charlie e 12 no Delta, totalizando 40.

Em termos operacionais, há uma dupla de praças responsáveis pelo patrulhamento e aproximação com a comunidade em cada um dos subsetores, o que totaliza 80 pessoas.

\footnotetext{
${ }^{6} \mathrm{Na}$ verdade, é importante deixar claro que o presente artigo avalia o efeito da $1^{\text {a }}$ CIPP sobre os crimes ocorridos na área da $20^{\text {a }}$ Delegacia de polícia, que compreende tanto o próprio território coberto pelo projeto piloto de policiamento de proximidade quanto outras localidades não contempladas pelo programa. Este assunto será tratado de maneira mais aprofundada na seção que discorre sobre a avaliação de impacto da $1^{\mathrm{a}}$ CIPP.

${ }^{7}$ Mais precisamente, toda CISP corresponde a área de circunscrição de uma Delegacia de Polícia (DP) de numeração idêntica. Na prática, para fins do presente artigo, pode-se considerar que não existe nenhuma distinção entre os termos delegacia, DP e CISP. Portanto, estas três terminologias (delegacia, DP e CISP) serão utilizadas como sinônimos ao longo do texto.

${ }^{8}$ Esse trabalho foi realizado pela PM3 (setor de planejamento operacional do Batalhão) em conjunto com o Comandante do $6^{\circ} \mathrm{BPM}$, Cel. Marcelo Rocha.
}

Econômica-Niterói, v. 19, n. 2, p. 87-110. dezembro, 2017 
A esse trabalho dá-se o nome de Policiamento Ostensivo Geral (POG). Além deles, a Companhia conta com 16 policiais no serviço de Ação Preventiva (APREV) motorizada, 8 em Motopatrulhas, e 14 na Supervisão, totalizando 118 policiais 9 .

Vale ressaltar, contudo, que o projeto piloto de polícia de proximidade não abrange toda a área da $20^{\mathrm{a}}$ CISP. A CIPP não abarca as áreas das UPP Andaraí, Macacos e parte do Borel, além da floresta da região, como demonstra a Figura 1. Com o reforço, a área do CIPP passou a contar com 103 policiais por 100 mil habitantes ${ }^{10}$. Como comparação, os batalhões da PMERJ contam em média com 88 policiais por 100 mil habitantes trabalhando na área fim e as UPP contam com 917 policiais por 100 mil habitantes. Se situarmos a $1^{\text {a }}$ CIPP entre os BPM tem-se que a companhia do projeto-piloto está em $20^{\circ}$ lugar entre as 40 unidades (39 batalhões mais a CIPP) em termos de número de policiais em área fim por 100 mil habitantes.

\section{Figura 1: Mapa da CIPP com subsetores, UPP e área de floresta}

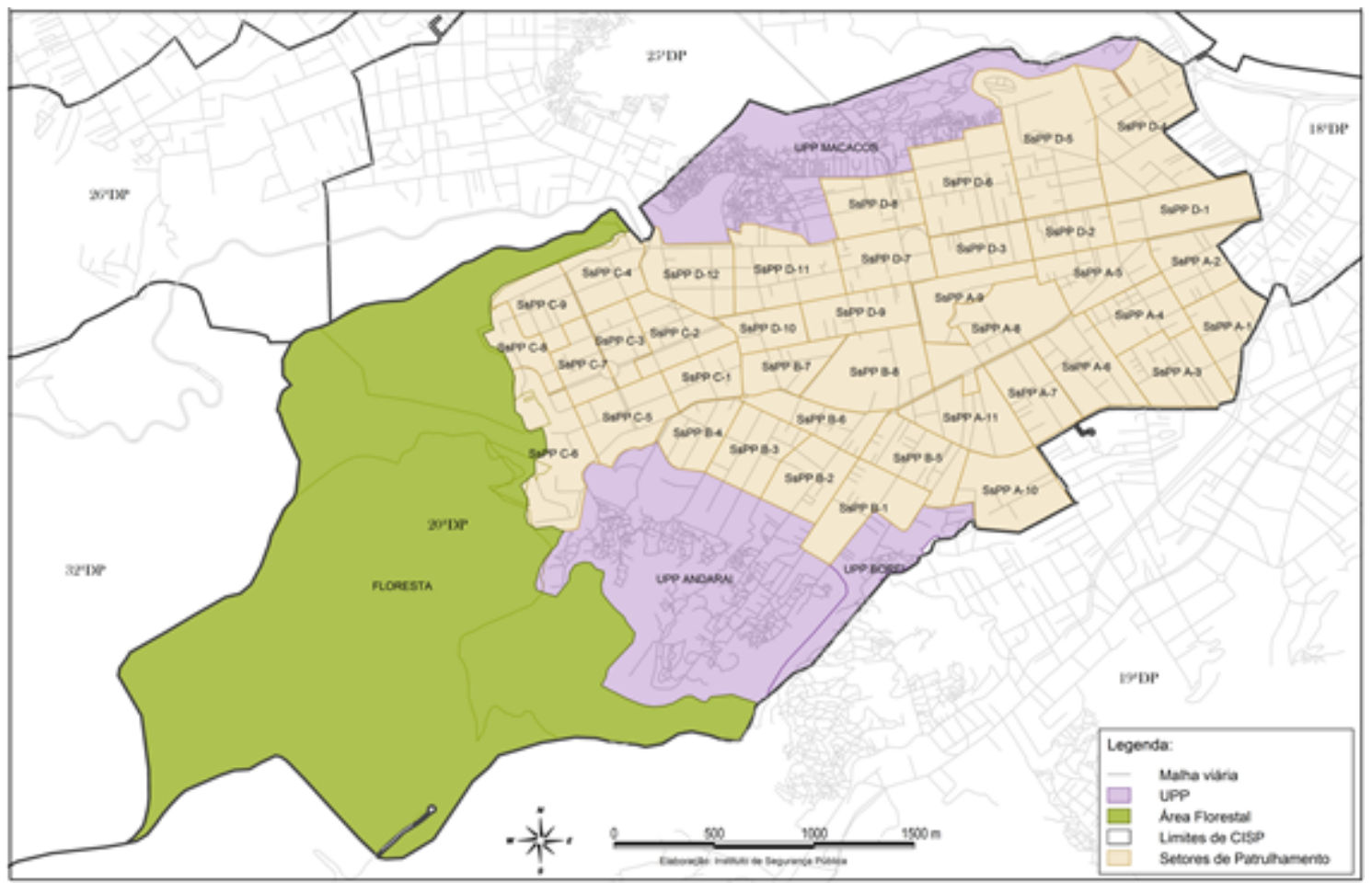

O comando da CIPP está sob responsabilidade de um Capitão, que possui autonomia operacional. Dessa forma, ele pode estabelecer escalas diferentes para os policiais do se-

\footnotetext{
${ }^{9}$ Ressalte-se que o $6{ }^{\circ}$ BPM perdeu $100 \%$ dos policiais do Regime Adicional de Serviço (RAS), que representavam 40 pessoas.

${ }^{10}$ Para calcular a população de 114 mil residentes da área da $1^{\text {a }}$ CIPP (utilizada na geração da taxa de policiais por 100.000 habitantes), realizou-se uma sobreposição entre os subsetores de polícia de proximidade e os setores censitários do IBGE. O valor se refere ao Censo de 2010.
} 
tor, alterar os horários de entrada dos policiais no POG, repassar as informações criminais e outras aos policiais, além de indicar as atividades a serem realizadas. Os serviços são repassados ao setor de planejamento operacional do Batalhão (a PM3), que confecciona as ordens de serviço. Todas as demais rotinas administrativas, de inteligência e planejamento são feitas pelo Batalhão, o que permite ao Comandante da CIPP se concentrar nos aspectos operacionais e de segurança pública. Ainda não há, até o momento, qualquer sistema de metas, objetivos e responsabilização para as diversas funções ocupadas na CIPP.

\subsection{O policiamento de proximidade}

Quanto à filosofia da polícia de proximidade, descrita na Instrução Normativa (IN) 22/2015 da PMERJ, ela se estrutura nos seguintes princípios: Prevenção, Descentralização, Proatividade e Resolução Pacífica de Conflitos. Estes se desdobram nas seguintes ações: a aproximação, presença, permanência, envolvimento e comprometimento. Esses elementos revelam a intenção de criar sinergia entre a sociedade local e os policiais, o que traria duas consequências positivas: o aumento da legitimidade institucional e a facilidade de encaminhamento de informações importantes por parte da população.

Para operacionalizar esses objetivos, os policiais no serviço POG trabalham, em sua maioria, em escalas de 5 X 2 ( 8 horas diárias por 5 dias, com 2 dias de descanso), realizam visitas a escolas, comércios e associações de vizinhança, participam de debates e eventos, e entregam cartões de visita aos moradores com seu número de telefone ${ }^{11}$ para serem acionados. Além disso, há sempre um policial responsável por telefonar para as vítimas de crimes na região. Idealiza-se ainda que os policiais fiquem, no mínimo, um ano no mesmo subsetor. Dentre as atividades, um dos pontos menos explorados dentro do projeto piloto parece ser a resolução pacífica de conflitos.

Observa-se que muitas dessas ações pretendem efetivar os princípios citados, ainda que não haja mecanismos institucionais para garanti-las. Dessa forma, torna-se difícil avaliar integralmente a consecução dos objetivos da Polícia de Proximidade descrito na IN 22/2015, a saber, a construção de confiança mútua entre policiais e cidadãos, a redução de crimes e de desvios de conduta. O presente artigo procura realizar uma avaliação de impacto de apenas um desses itens: a queda no número de crimes.

\subsection{O policiamento orientado ao problema}

O último elemento estruturante do projeto piloto é o policiamento orientado ao problema. Objetiva-se que o planejamento operacional seja realizado baseado nos problemas identificados e considerados mais importantes, que depois terão suas ações monitoradas,

\footnotetext{
${ }^{11}$ Os telefones institucionais foram entregues apenas aos policiais dos subsetores do setor Alpha, Charlie e Delta.
}

Econômica-Niterói, v. 19, n. 2, p. 87-110. dezembro, 2017 
avaliadas e consideradas quanto à manutenção ${ }^{12}$. Em princípio, essas etapas deveriam ocorrer com todos os atores capazes de atuar nos problemas considerados: policiais civis e militares, agentes da prefeitura, guardas municipais, membros da secretaria de segurança e, em alguns momentos, organizações civis.

$\mathrm{Na} 1^{\mathrm{a}}$ CIPP do $6^{\circ}$ BPM a coordenação estava a cargo do Comandante da CIPP em conjunto com um consultor externo ${ }^{13}$. As reuniões permitiram a identificação de algumas dificuldades na implementação da CIPP e o desenho de estratégias para combatê-las. Entretanto, as ações idealizadas somente foram realizadas pela PMERJ, o que demonstra as fragilidades do atual modelo de parceria operacional entre os diferentes atores mencionados no parágrafo anterior.

\section{Avaliação de impacto da CIPP}

\subsection{Dados}

A $1^{\text {a }}$ CIPP consiste em um programa de policiamento comunitário, cujo impacto tende a incidir sobre crimes que, como os acompanhados pelo Sistema Integrado de Metas (SIM), são influenciados pela presença e confiabilidade do policial. Desta maneira, a variável utilizada para avaliar o efeito deste novo programa de policiamento de proximidade é construída, justamente, a partir da agregação das ocorrências referentes aos crimes acompanhados pelo SIM. Mais precisamente, determina-se o impacto do projeto sobre a taxa de ocorrências, que é uma taxa por 100.000 habitantes com periodicidade mensal, produzida a partir da soma dos crimes incluídos nas seguintes categorias: (i) letalidade violenta (vítimas), (ii) roubos de rua (casos) e (iii) roubos de veículo (casos) ${ }^{141516}$.

Para avaliar o impacto da $1^{\text {a }}$ CIPP sobre o crime são utilizadas três fontes de dados distintas. A primeira, que permite construir a taxa de ocorrências do SIM, é produzida pelo ISP a partir dos dados disponibilizados pelo Departamento Geral de Tecnologia da Informação e Telecomunicações (DGTIT) da Polícia Civil do Estado do Rio de Janeiro

\footnotetext{
${ }^{12} \mathrm{Na}$ IN 22/2015 e outras normativas sobre a Polícia de Proximidade é sugerido o uso da técnica IARA (Identificação, Análise, Resposta e Avaliação).

${ }^{13}$ A consultoria ao projeto foi realizada pela Fundação Brava, representada pelo cientista político Leandro Piquet.

${ }^{14} \mathrm{O}$ indicador de letalidade violenta é o somatório dos seguintes crimes: homicídio doloso, autos de resistência, roubo seguido de morte (ou latrocínio) e lesão corporal seguida de morte.

${ }^{15}$ A população mensal por delegacia, variável necessária para determinar a taxa de ocorrências, é calculada pelo próprio ISP com base nos Censos Demográficos do IBGE de 2000 e de 2010. Para maiores detalhes acerca da metodologia utilizada pelo ISP para gerar a população mensal por delegacia ver o seguinte link: "http://www.ispdados.rj.gov.br/Populacao.html”.

${ }^{16}$ A seguinte fórmula foi utilizada para calcular a taxa de ocorrências $t x d e o c o r r_{i t}$, por 100 mil habitantes, na delegacia $i$ no mês $t$ :

$t_{x d e o c o r r}{ }_{i t}=\left(\frac{\text { letalidade violenta }_{i t}+\text { roubo de rua }_{i t}+\text { roubo deveículo }_{i t}}{\text { população }_{i t}}\right)$
}

Econômica-Niterói, v. 19, n. 2, p. 87-110. dezembro, 2017 
(PCERJ). Esta base compreende ocorrências mensais de crimes no estado do Rio de Janeiro, agregadas no nível da delegacia, e registradas entre abril de 2014 e setembro de 2015. É importante fazer três observações acerca dos dados produzidos pelo ISP. Primeiro, para garantir uma análise limitada a um conjunto de unidades que sejam comparáveis, restringe-se a amostra às delegacias da capital.

Segundo, o presente estudo assume que as informações agregadas no nível da delegacia permitem avaliar o efeito da $1^{\text {a }}$ CIPP, sobre o seu próprio território, visto que existe uma grande semelhança entre a área coberta por este novo programa de policiamento de proximidade e a pertencente a $20^{\mathrm{a}}$ CISP. No entanto, na verdade o presente artigo avalia o efeito da implementação da $1^{\text {a }}$ CIPP sobre os crimes ocorridos na $20^{a}$ CISP. Para poder garantir que o impacto da $1^{\text {a }}$ CIPP, sobre os crimes ocorridos no seu próprio território, seja idêntico ao efeito deste programa de policiamento de proximidade, sobre os delitos observados na $20^{\text {a }}$ CISP, é necessário fazer uma hipótese adicional. Mais precisamente, para garantir que o presente estudo esteja efetivamente captando o efeito da $1^{\text {a }} \mathrm{CIPP}$, sobre o seu próprio território, é necessário assumir que não exista nenhuma externalidade do referido programa de policiamento de proximidade, sobre os crimes das demais áreas da $20^{\text {a }}$ CISP. Alternativamente, caso exista externalidade da $1^{\text {a }}$ CIPP sobre os crimes ocorridos nas demais áreas da $20^{\mathrm{a}} \mathrm{CISP}$, pode-se interpretar o efeito estimado neste artigo como representando o impacto agregado do programa tanto sobre o seu próprio território quanto sobre os outros espaços da mesma delegacia ${ }^{17}$.

Finalmente, o período de análise começa em abril de 2014, dado que a ocupação para a implantação da última Unidade de Polícia Pacificadora (UPP) ocorreu em março de 2014. Logo, a eliminação dos meses anteriores a abril de 2014 ajuda a reduzir os possíveis efeitos da política de pacificação sobre os resultados desta pesquisa. Além disso, o período estudado termina em setembro de 2015, pois este é último mês em que a equipe responsável pela avaliação de impacto da CIPP esteve em campo. Vale ressaltar, que a presença física da equipe de avaliação na CIPP revelou-se extremamente importante, visto que ajudou a confirmar que os recursos, e procedimentos, estavam realmente sendo aplicados na forma concebida originalmente pelos idealizadores do programa. Assim, fica claro que seria um equívoco prosseguir com a avaliação da CIPP, após setembro de 2015,visto que já não havia mais nenhuma maneira eficaz de garantir, a partir de outubro do mesmo ano, que estava sendo dado prosseguimento adequado ao programa.

As demais fontes de dados permitem determinar um conjunto de características, para cada delegacia, cuja importância será descrita na próxima seção. A segunda base de dados é desenvolvida a partir do Censo Demográfico de 2010, que é produzido pelo Instituto Brasileiro de Geografia e Estatística (IBGE). As informações disponibilizadas por setor

\footnotetext{
${ }^{17}$ Note que se optou por utilizar os dados no nível da delegacia, apesar da diferença entre a área da $20^{\text {a }}$ CISP e o território da $1^{\text {a }}$ CIPP, pelo fato que as referidas informações, agregadas por CISP, estão disponibilizadas pelo ISP na internet e, portanto, podem ser facilmente acessadas por qualquer pessoa interessada em replicar os resultados do presente estudo. A facilidade de reproduzir esta pesquisa confere maior grau de transparência aos resultados obtidos aqui.
}

Econômica-Niterói, v. 19, n. 2, p. 87-110. dezembro, 2017 
censitário são agregadas para o nível da delegacia, para tornar os dados do IBGE compatíveis com os do ISP. Este procedimento permite construir as seguintes variáveis para cada delegacia: (i) índice de Gini, (ii) proporção de chefes de domicílio alfabetizados, (iii) proporção da população que tem entre 15 e 24 anos de idade e (iv) log da renda per capita $^{18}$.

O terceiro conjunto de informações advém de dados disponibilizados, para o ano de 2010, pelo Instituto Pereira Passos (IPP). Estes dados contêm tanto a área quanto a população de todas as favelas do município do Rio de Janeiro. Portanto, as informações fornecidas pelo IPP permitem, quando utilizadas conjuntamente com o Censo de 2010 (especificamente, os dados disponibilizados para os setores censitários e compatibilizados para o nível das CISP), construir as seguintes variáveis para cada delegacia: (i) proporção da população de favelas vivendo em territórios pacificados e (ii) proporção da área de favelas compreendida por territórios pacificados.

\subsection{Metodologia}

O objetivo deste trabalho é determinar o efeito da implementação da $1^{\text {a }}$ CIPP sobre a taxa de ocorrências do SIM. A principal dificuldade para avaliar o impacto da introdução deste novo programa de policiamento de proximidade na área da $20^{a}$ CISP é o fato de que inúmeros fatores, que também afetam a evolução da criminalidade, podem mudar tanto no momento quanto após a introdução da $1^{\text {a }}$ CIPP. Por este motivo, torna-se impossível atribuir eventuais reduções (ou aumentos) na taxa de ocorrências unicamente à instauração do programa. Uma metodologia tradicionalmente utilizada para lidar com este tipo de dificuldade consiste em comparar a evolução da taxa de ocorrências da área afetada pelo projeto (a 20 CISP) com a de localidades não afetadas (as outras delegacias da capital). Este último conjunto, composto por localidades não afetadas, é também geralmente chamado de grupo de controle. Porém, a busca por um grupo de controle não é trivial. Deve-se buscar comparar a área afetada com outras que são semelhantes e que diferem apenas na inexistência da política.

\footnotetext{
${ }^{18} \mathrm{O}$ IBGE, ao realizar o Censo, define os chamados setores censitários, que são unidades geográficas bastante pequenas, e fornecem uma amostra representativa da população que neles habita. Esta amostra permite produzir um conjunto bastante expressivo de informações acerca da população residente em cada setor censitário. Logo, é possível gerar o mesmo conjunto de informações por delegacia bastando, para isso, realizar uma agregação de todos os setores censitários contidos dentro da área de cada delegacia. Foi exatamente este tipo de procedimento de agregação, realizado com o Censo de 2010, que permitiu o cálculo das características utilizadas no presente texto para cada delegacia (lembrando que as características utilizadas são: gini, proporção de chefes de domicílio alfabetizados, proporção da população que tem entre 15 e 24 anos de idade e log da renda per capita). A fórmula, abaixo, ilustra como foi feita a compatibilização mencionada para o caso da proporção de chefes de domicílio alfabetizados. Em linhas gerais, somou-se, para a delegacia $i$, os dados de todos os setores censitários $j$ contidos na sua área de responsabilidade. Mais precisamente, procedeu-se da seguinte maneira:

Proporção chefes alfabetizados $_{i}=\frac{\sum_{j} N^{o} \text { chefes } \text { alfabetizados }_{j i}}{\sum_{j} N^{o} \text { chefes }_{j i}}$
} 
Figura 2: Evolução da Taxa de Ocorrências para: a 20ª CISP, Algumas Delegacias Localizadas nas Cercanias da $20^{\text {a }}$ CISP e a Capital.

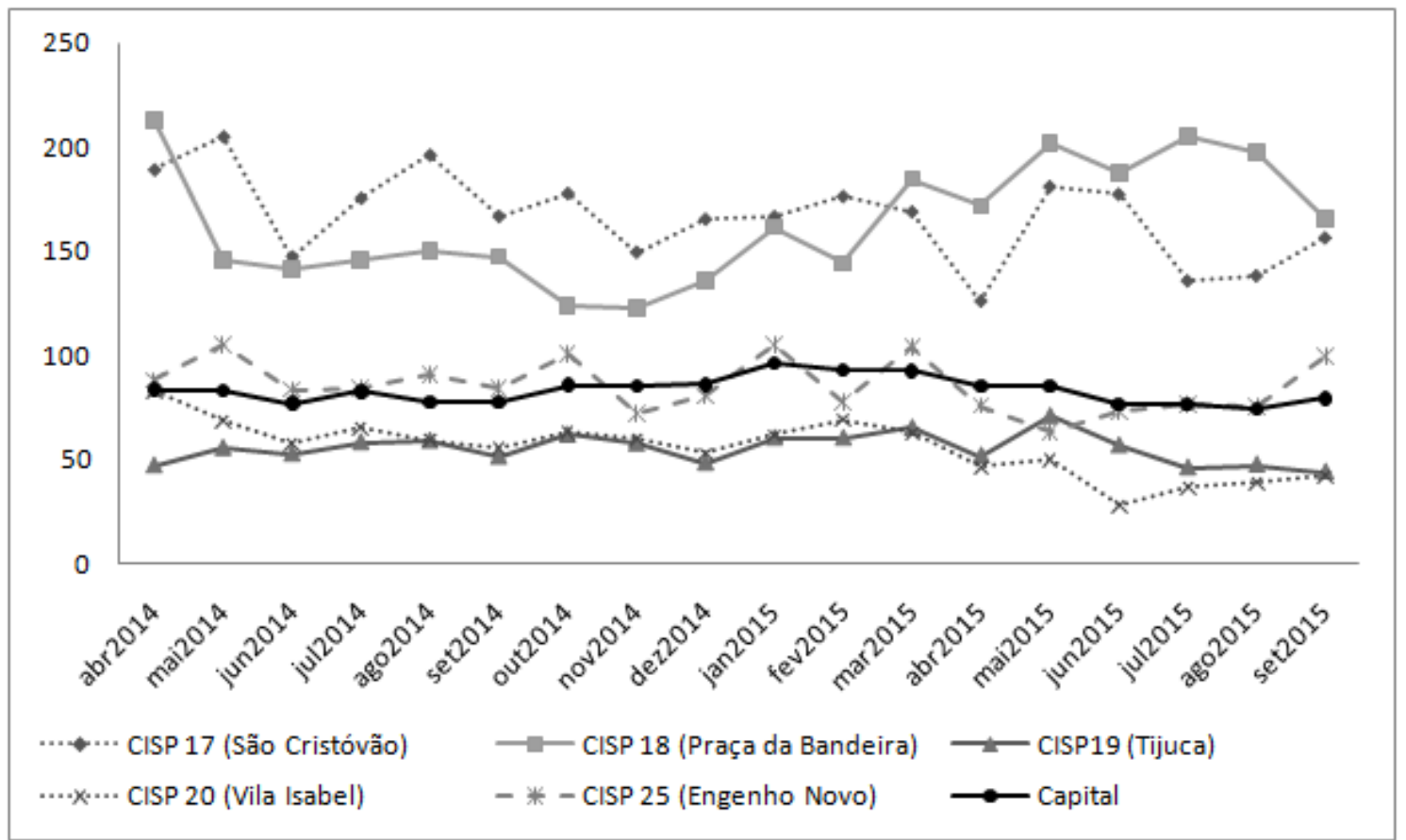

A Figura 2 apresenta a evolução da taxa de ocorrências para as seguintes regiões geográficas: (i) a 20ª CISP, (ii) algumas das CISP localizadas nas cercanias da $20^{\mathrm{a}}$ e (iii) para a capital como um todo. A figura mostra, por exemplo, que seria possível construir um grupo de controle baseado unicamente na $19^{\mathrm{a}} \mathrm{CISP}$, com sede na Tijuca, visto que esta unidade é semelhante à $20^{a}$ CISP. Ambas as CISP são parecidas, no período anterior à implementação da $1^{\mathrm{a}} \mathrm{CIPP}$, tanto em termos absolutos da taxa de ocorrências quanto com relação à evolução desta variável. Porém, não é prudente construir um grupo de controle baseado exclusivamente na $19^{\text {a }}$ CISP (Tijuca) visto que, no período considerado nesta pesquisa, ainda existiam planos de incluir a delegacia em questão, no programa das CIPP. Esta expectativa mostrou-se frustrada, visto que o projeto da CIPP nunca avançou para além da $20^{\text {a }}$ CISP. Porém, a perspectiva, existente na $19^{\text {a }}$ CISP, de receber a segunda unidade do programa das CIPP poderia alterar os incentivos dos policiais alocados na área desta última delegacia. A possibilidade de alteração na dinâmica criminal na área da $19^{\text {a }}$ CISP, em virtude, da expectativa de recebimento da segunda CIPP desqualifica a utilização da referida delegacia para construção do grupo de controle.

Outra alternativa seria criar um grupo de controle baseado nas outras delegacias da capital $^{19}$. No entanto, a Figura 3 sugere que o conjunto formado pelas outras delegacias

\footnotetext{
${ }^{19} \mathrm{O}$ conjunto das outras delegacias da capital é composto pelas seguintes unidades: $1^{\mathrm{a}} \mathrm{CISP}, 4^{\mathrm{a}} \mathrm{CISP}$, $5^{\mathrm{a}}$ CISP, $6^{\mathrm{a}}$ CISP, $7^{\mathrm{a}}$ CISP, $9^{\mathrm{a}}$ CISP, $10^{\mathrm{a}}$ CISP, $12^{\mathrm{a}}$ CISP, $13^{\mathrm{a}}$ CISP, $14^{\mathrm{a}}$ CISP, $15^{\mathrm{a}}$ CISP, $16^{\mathrm{a}}{\text { CISP, } 17^{\mathrm{a}}}$
}

Econômica-Niterói, v. 19, n. 2, p. 87-110. dezembro, 2017 
da capital não é um grupo de comparação apropriado para a $20^{\mathrm{a}}$ CISP. Isto porque, mesmo antes da inauguração da $1^{\mathrm{a}}$ CIPP já existia uma diferença expressiva entre a trajetória da taxa de ocorrências da $20^{\text {a }}$ CISP e das outras delegacias da capital. Mais precisamente, a taxa de ocorrências era semelhante nos dois grupos em abril de 2014. Porém, no final daquele ano (dezembro de 2014) já vigorava uma diferença expressiva entre a taxa de ocorrências observada nestas duas localidades.

Figura 3: Evolução da Taxa de Ocorrências para a 20ª CISP e para as Outras Delegacias da Capital.

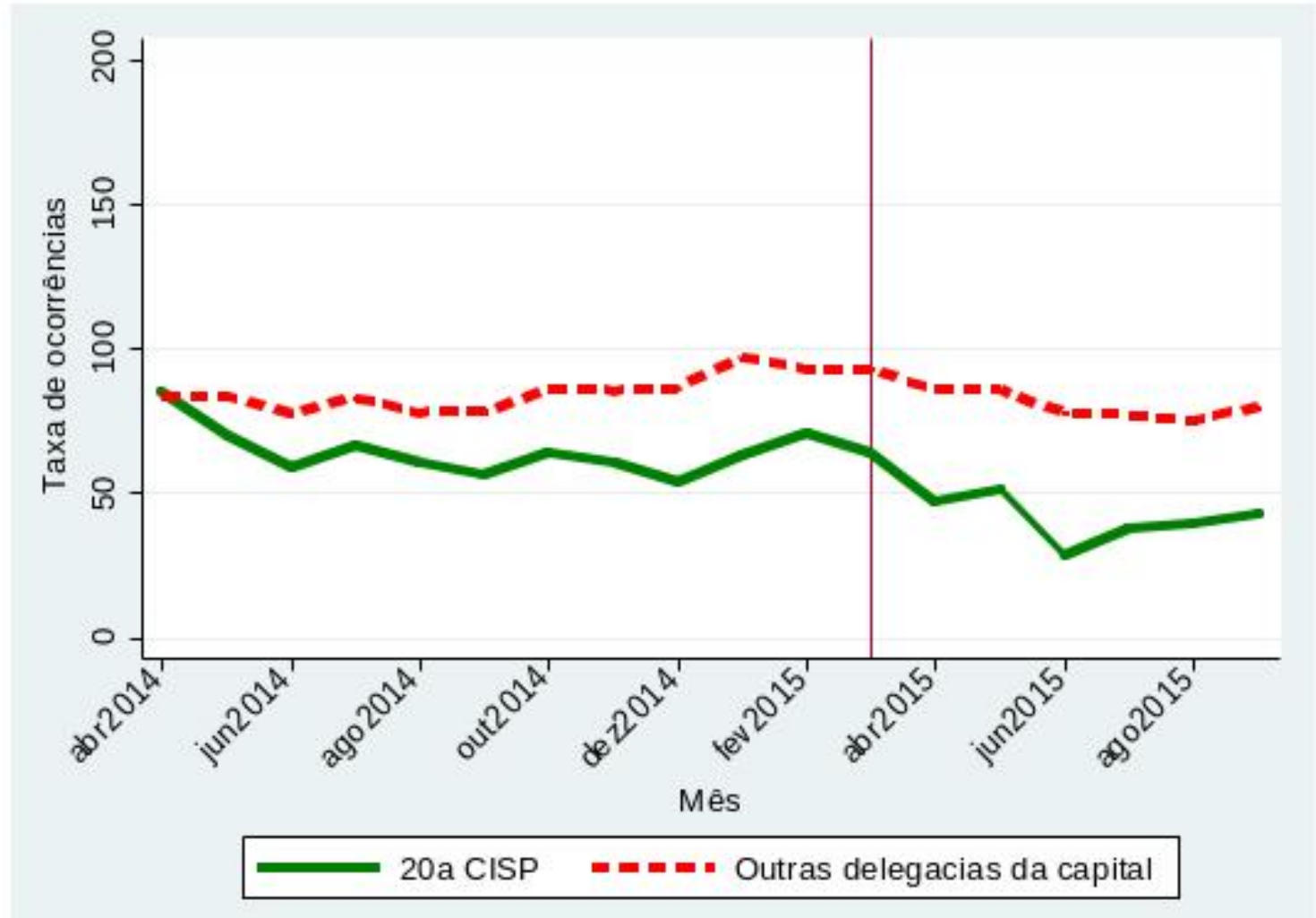

A Tabela 1 confirma a existência de uma diferença substantiva entre a $20^{\text {a }}$ CISP e as outras delegacias da capital, não só para a taxa de ocorrências, como também para um conjunto pré-determinado de características. Por exemplo, comparando-se as colunas 1 e

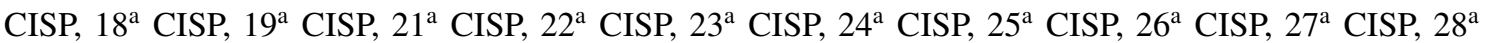
CISP, $29^{\mathrm{a}}$ CISP, $30^{\mathrm{a}}$ CISP, $31^{\mathrm{a}}$ CISP, $32^{\mathrm{a}}$ CISP, $33^{\mathrm{a}}$ CISP, $34^{\mathrm{a}}$ CISP, $35^{\mathrm{a}}$ CISP, $36^{\mathrm{a}}$ CISP, $37^{\mathrm{a}}$ CISP, $38^{\mathrm{a}}$ CISP, $39^{\mathrm{a}}$ CISP, $40^{\mathrm{a}} \mathrm{CISP}, 41^{\mathrm{a}} \mathrm{CISP}, 42^{\mathrm{a}}$ CISP, $43^{\mathrm{a}}$ CISP e $44^{\mathrm{a}}$ CISP. Para maiores informações acerca das diferentes delegacias da capital recomenda-se ver, no anexo, tanto a Figura 1A quanto a Tabela 1A. Mais precisamente, a Figura 1A, apresenta um mapa indicando a localização geográfica das referidas delegacias. Já a Tabela 1A fornece, para cada uma das delegacias em questão, tanto uma lista dos bairros contidos na sua área de cobertura quanto o nome do bairro em que fica localizada a sua sede. 
4 constata-se que apenas $46 \%$ da população de favelas vive em territórios pacificados nas outras delegacias da capital, enquanto este percentual é de aproximadamente $99 \%$ na $20^{\text {a }}$ CISP. Além disso, os indivíduos da $20^{\text {a }}$ CISP são em média mais ricos. Nesta delegacia o log da renda per capita é de 7,5 enquanto nas outras delegacias da capital esta mesma variável assume o valor de 7. Consequentemente, permanece a dúvida acerca de quais delegacias devem ser incluídas no grupo de controle de uma eventual tentativa de avaliar o impacto da $1^{\text {a }}$ CIPP. 
Tabela 1: Comparação de Características Selecionadas

\begin{tabular}{|c|c|c|c|c|}
\hline & 20a CISP & $\begin{array}{l}\text { Controle } \\
\text { sintético da } \\
20 \mathrm{a} \text { CISP }\end{array}$ & $\begin{array}{l}\text { Conjunto de } \\
\text { delegacias } \\
\text { semelhantes }\end{array}$ & $\begin{array}{c}\text { Outras } \\
\text { delegacias } \\
\text { da capital } \\
\end{array}$ \\
\hline & (1) & (2) & (3) & (4) \\
\hline $\begin{array}{l}\text { Proporção da população de favelas vivendo em } \\
\text { territórios pacificados }{ }^{\mathrm{a}}\end{array}$ & 0,991 & 0,990 & 0,927 & 0,463 \\
\hline $\begin{array}{l}\text { Proporção da área de favelas compreendida por } \\
\text { territórios pacificados }{ }^{\mathrm{a}}\end{array}$ & 0,998 & 0,981 & 0,926 & 0,453 \\
\hline Gini $^{b}$ & 0,332 & 0,332 & 0,340 & 0,329 \\
\hline Proporção de chefes alfabetizados ${ }^{b}$ & 0,972 & 0,972 & 0,969 & 0,969 \\
\hline $\begin{array}{l}\text { Proporção da população que tem entre } 15 \text { e } 24 \\
\operatorname{anos}^{b}\end{array}$ & 0,135 & 0,135 & 0,144 & 0,148 \\
\hline Log da renda per capita ${ }^{b}$ & 7.542 & 7.599 & 7.277 & 7.073 \\
\hline $\begin{array}{l}\text { Taxa média de ocorrências entre junho e julho de } \\
2014^{c}\end{array}$ & 62.353 & 63.255 & 195.984 & 141.271 \\
\hline \multicolumn{5}{|c|}{ 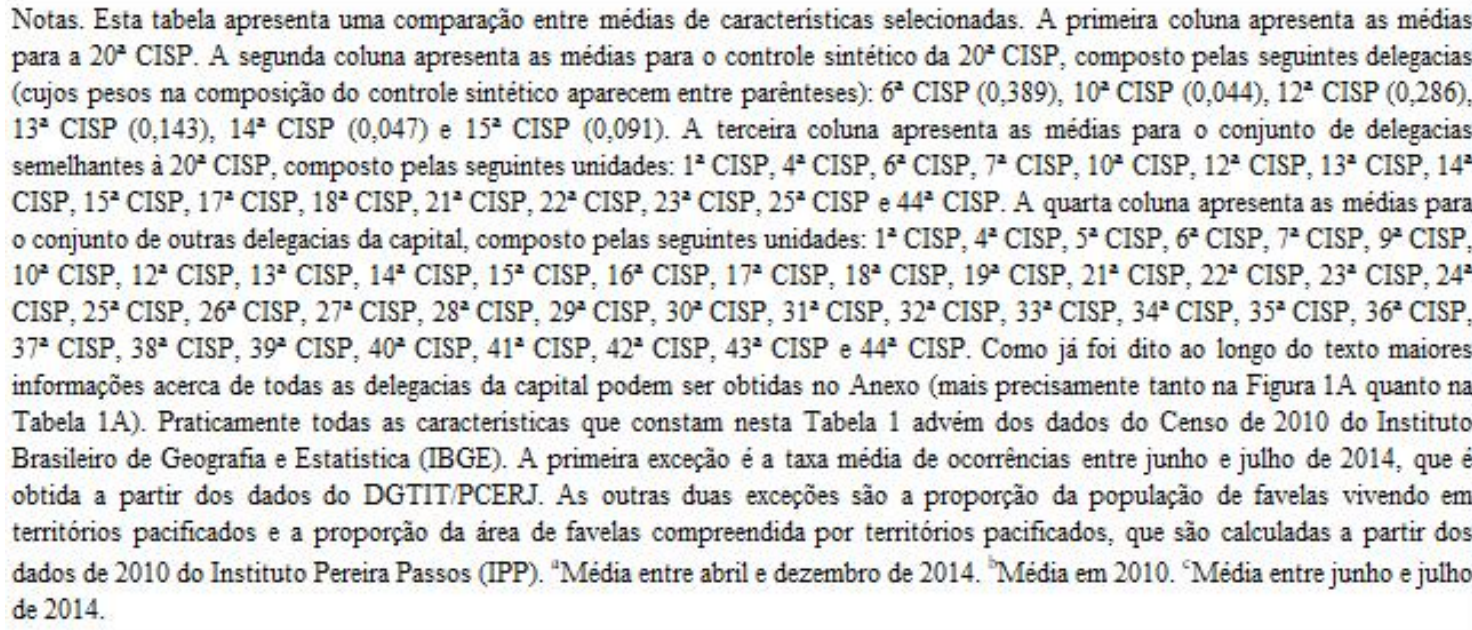 } \\
\hline
\end{tabular}


Para determinar o efeito da $1^{\mathrm{a}}$ CIPP sobre a taxa de ocorrências seria necessário saber como esta variável teria evoluído na $20^{\text {a }}$ CISP, depois de março de 2015 , caso a $1^{\text {a }}$ CIPP não tivesse sido implementada. O método de controle sintético provê uma maneira sistemática para estimar este contrafactual (para maiores detalhes acerca do funcionamento do controle sintético ver, por exemplo,o artigo seminal de Abadie e Gardeazabal, 2003). Mais precisamente, este método busca um vetor de pesos, a ser atribuído às unidades não afetadas, obtendo-se como resultado o chamado grupo de controle sintético. A principal vantagem deste grupo é ser semelhante à unidade afetada, no período anterior à implementação do programa. Busca-se garantir semelhança nas seguintes dimensões: (i) em termos absolutos para um conjunto pré-determinado de características e (ii) com relação à evolução de uma variável de interesse previamente selecionada.

O conjunto pré-determinado de características, selecionado em função de sua potencial ligação com o nível observado de criminalidade em cada delegacia, e incluído no método de controle sintético é composto pelas seguintes variáveis: (i) índice de gini, (ii) proporção de chefes de domicílio alfabetizados, (iii) proporção da população que tem entre 15 e 24 anos de idade, (iv) $\log$ da renda per capita, (v) proporção da população de favelas vivendo em territórios pacificados e (vi) proporção da área de favelas compreendida por territórios pacificados ${ }^{20}$. Outra variável incluída no modelo é a taxa média de ocorrências entre junho e julho de 2014 que visa controlar para o período da Copa do Mundo. Além disso, o modelo contém, como variável de interesse previamente selecionada, a taxa de ocorrências (calculada a partir da soma de todas as categorias de crime acompanhadas pelo SIM).

O método de controle sintético tem sido extensivamente utilizado na avaliação de impacto de políticas públicas, como discutido de maneira mais aprofundada por Abadie e Gardeazabal (2003) e Abadie et al (2010). Estes artigos, elaborados pelos próprios responsáveis pela criação do método de controle sintético, sugerem que o desempenho do referido procedimento pode ser aprimorado através da utilização de um conjunto inicial de áreas não afetadas que seja relativamente parecido com a localidade afetada.

\footnotetext{
${ }^{20}$ Algumas sugestões de artigo, que corroboram as variáveis selecionadas para serem incluídas no método de controle sintético, são: (i) Kelly (2000) e Fajnzylber et al (2002), que fornecem evidência de correlação positiva entre a desigualdade e o crime (resultado que corrobora a decisão de incorporar o índice de gini nas variáveis selecionadas), (ii) Chiras e Crea (2004), que encontram efeito negativo da educação sobre o crime (evidência que respalda a inclusão, no conjunto de variáveis selecionadas, da proporção de chefes de domicílio que são alfabetizados), (iii) Grogger (1998), cujo modelo econométrico ajuda a explicar a elevada participação de jovens na atividade criminosa (fato que valida a decisão de considerar, na lista de variáveis selecionadas, a proporção da população que tem entre 15 e 24 anos de idade), (iv) Becker (1968), que sugere, em seu trabalho seminal sobre economia do crime, a existência de uma relação negativa entre salário e crime (evidência que respalda a inclusão, no conjunto de variáveis selecionadas, do logaritmo da renda per capita) e (v) Borges et al (2012) e Ottoni (2014), que fornecem evidência de que a implementação das Unidades de Polícia Pacificadora (UPP) ajudou a reduzir o crime nas áreas ocupadas pelas forças de segurança do estado (resultado que corrobora a opção por incluir, na lista de variáveis selecionadas, indicadores que ajudam a auferir o grau de penetração da política de pacificação em cada delegacia).
}

Econômica-Niterói, v. 19, n. 2, p. 87-110. dezembro, 2017 
$\mathrm{O}$ conjunto de delegacias semelhantes à $20^{\mathrm{a}}$ CISP surge justamente como uma tentativa de aprimorar o desempenho do método de controle sintético. Este grupo de delegacias é um subconjunto das outras delegacias da capital e resulta da eliminação das unidades que atendem às seguintes condições: (i) $50 \%$ ou menos da proporção da população de favelas reside em territórios pacificados ou (ii) $50 \%$ ou menos da proporção da área de favelas é composta por territórios pacificados. Basicamente, procede-se com a exclusão de delegacias com pouca (ou nenhuma) presença das UPP, dado que o principal objetivo é construir um grupo de controle semelhante à $20^{\mathrm{a}}$ CISP e que esta última é intensamente afetada pelo programa de pacificação. Além disso, também eliminou-se a $19^{\text {a }}$ CISP do conjunto de delegacias semelhantes, visto que, como dito anteriormente, ainda existiam planos de incluir a referida delegacia no programa das CIPP, durante período considerado no presente estudo.

A coluna 3 da Tabela 1 apresenta estatísticas descritivas referentes ao conjunto de delegacias semelhantes à $20^{\text {a }}$ CISP. Pode-se perceber que este grupo de delegacias é significativamente mais parecido com a $20^{\text {a }}$ CISP do que o conjunto das outras delegacias da capital. Por exemplo, apenas $46 \%$ da população de favelas vive em territórios pacificados nas outras delegacias da capital enquanto cerca de $93 \%$ das pessoas moram em favelas pacificadas no conjunto de delegacias semelhantes, número que é muito mais parecido com os $99 \%$ observados para esta variável na $20^{a}$ CISP $^{21}$.

\subsection{Resultados}

As características da versão sintética da $20^{\text {a }}$ CISP, construída a partir de uma combinação convexa entre as unidades pertencentes ao conjunto de delegacias semelhantes, são fornecidas na coluna 2 da Tabela 1 . Pode-se perceber que o método de controle sintético é muito bem-sucedido na determinação de um grupo de controle parecido com a $20^{\mathrm{a}}$ CISP. Independentemente da característica analisada e, considerando-se o período anterior à implementação da $1^{\mathrm{a}}$ CIPP, observa-se médias praticamente idênticas entre a $20^{\mathrm{a}}$ CISP e o controle sintético desta unidade. A Figura 4 mostra que o controle sintético da $20^{a}$ CISP é semelhante a esta unidade, no período anterior à implementação da $1^{\mathrm{a}} \mathrm{CIPP}$, não só em termos de características pré-determinadas, mas também com relação ao nível e a evolução da taxa de ocorrências.

A Tabela 2 fornece o peso de cada delegacia incluída no controle sintético da $20^{\text {a }}$ CISP. Os pesos apresentados na tabela indicam que a trajetória da taxa de ocorrências da $20^{\mathrm{a}} \mathrm{CISP}$, antes da introdução da $1^{\mathrm{a}} \mathrm{CIPP}$, é reproduzida mais fielmente por uma combina-

\footnotetext{
${ }^{21} \mathrm{O}$ conjunto de delegacias semelhantes é composto pelas seguintes unidades: $1^{\mathrm{a}} \mathrm{CISP}, 4^{\mathrm{a}} \mathrm{CISP}, 6^{\mathrm{o}} \mathrm{CISP}$, $7^{\mathrm{a}}$ CISP, $10^{\mathrm{a}}$ CISP, $12^{\mathrm{a}}$ CISP, $13^{\mathrm{a}}$ CISP, $14^{\mathrm{a}}$ CISP, $15^{\mathrm{a}}$ CISP, $17^{\mathrm{a}}$ CISP, $18^{\mathrm{a}}$ CISP, $21^{\mathrm{a}}$ CISP, $22^{\mathrm{a}}$ CISP, $23^{\mathrm{a}}$ CISP, $25^{\mathrm{a}}$ CISP e $44^{\mathrm{a}}$ CISP. Como dito anteriormente, maiores informações sobre todas as delegacias da capital e, portanto, também para o conjunto de delegacias semelhantes (visto que estas últimas estão contidas no primeiro grupo), podem ser obtidas no anexo deste texto (mais precisamente, tanto na Figura 1A quanto na Tabela 1A).
} 
Figura 4: Evolução da Taxa de Ocorrências para a 20ª CISP e para o Controle Sintético da $20^{\text {a }}$ CISP

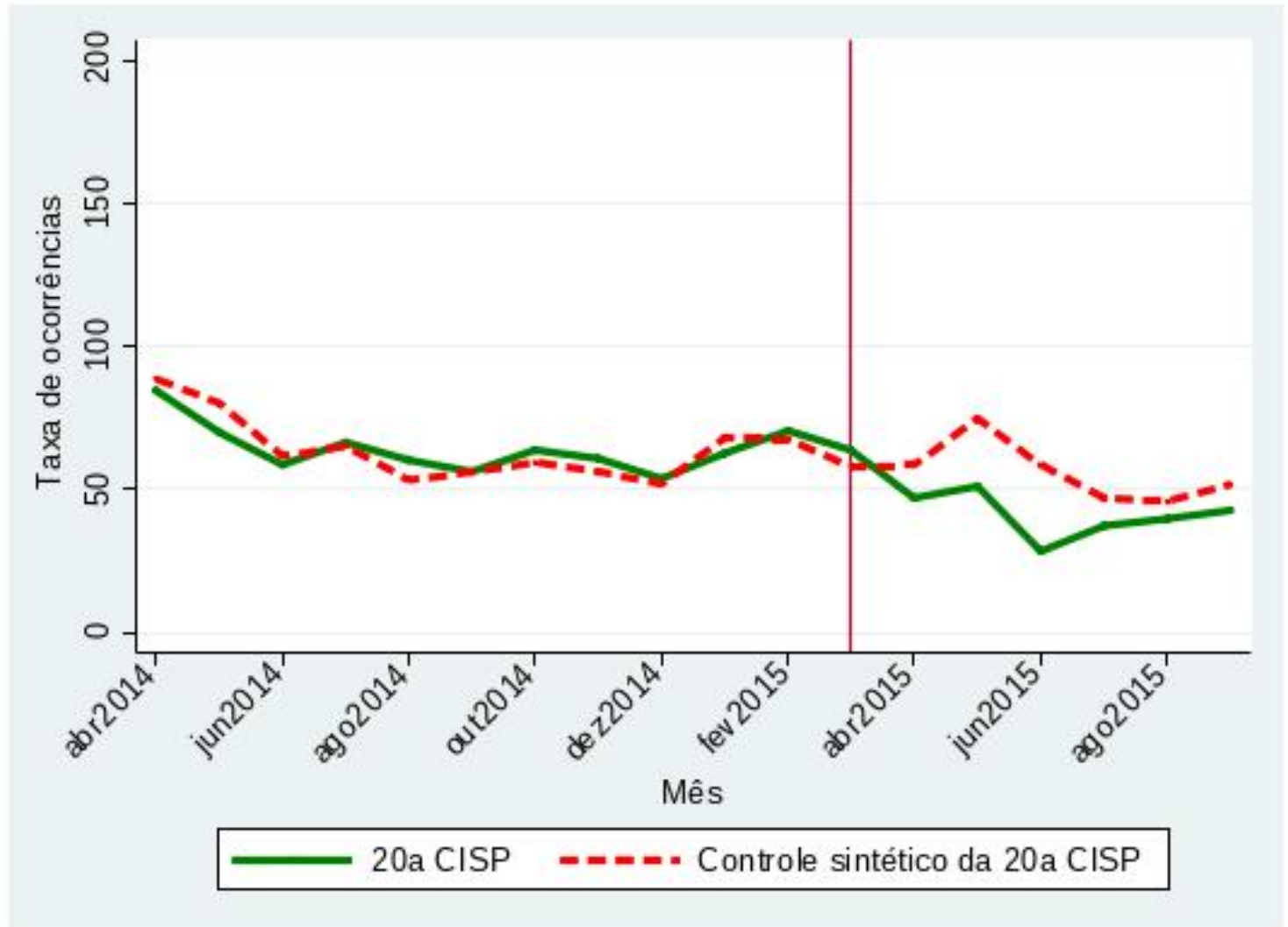

ção contendo a $6^{\mathrm{a}}$ CISP (Cidade Nova), a $10^{\mathrm{a}}$ CISP (Botafogo), a $12^{\mathrm{a}}$ CISP (Copacabana), a $13^{\text {a }}$ CISP (Ipanema), a $14^{\text {a }}$ CISP (Leblon) e a $15^{\text {a }}$ CISP (Gávea) ${ }^{22}$. Todas as outras unidades contidas no conjunto de delegacias semelhantes recebem peso zero. As demais unidades, pertencentes a capital, não recebem qualquer atribuição de peso, visto que foram excluídas da amostra antes mesmo da adoção do método de controle sintético. Estas unidades compreendem a 19 ${ }^{\mathrm{a}}$ CISP (Tijuca), excluída pelo motivo já elencado previamente de haver previsão para introdução de uma CIPP na área desta delegacia no período considerado no presente estudo, e as unidades eliminadas do conjunto de delegacias semelhantes, por terem pouca (ou nenhuma) presença de UPPs.

Intuitivamente, a trajetória da taxa de ocorrências no controle sintético representa o

\footnotetext{
${ }^{22}$ Mais precisamente, o controle sintético da $20^{\text {a }}$ CISP é composto pelas seguintes delegacias (cujos pesos, na composição do referido grupo de controle, aparecem entre parênteses): $6^{\mathrm{a}}$ CISP $(0,389), 10^{\mathrm{a}}$ CISP (0,044), $12^{\mathrm{a}}$ CISP (0,286), $13^{\mathrm{a}}$ CISP $(0,143), 14^{\mathrm{a}}$ CISP $(0,047)$ e $15^{\mathrm{a}}$ CISP $(0,091)$. Como dito anteriormente, maiores informações sobre todas as delegacias da capital e, portanto, também para aquelas contidas no controle sintético da $20^{\mathrm{a}} \mathrm{CISP}$ (visto que estas últimas pertencem ao primeiro grupo), podem ser obtidas no anexo deste texto (mais precisamente, tanto na Figura 1A quanto na Tabela 1A).
}

Econômica-Niterói, v. 19, n. 2, p. 87-110. dezembro, 2017 
Tabela 2: Peso das Diferentes Delegacias no Controle Sintético da 20ª CISP

\begin{tabular}{|c|c|c|c|c|c|c|c|}
\hline CISP & Bairro da Sede & Bairros na Área de Cobertura & Peso* & CISP & Bairro da Sede & Bairros na Área de Cobertura & Peso* \\
\hline 1 & Praça Mauá & Centro (Parte) & 0,000 & 25 & Engenho Novo & $\begin{array}{l}\text { Engenho Novo, Jacaré, Jacarezinho, Riachuelo, } \\
\text { Rocha, Sampaio e São Francisco Xavier }\end{array}$ & 0,000 \\
\hline 4 & $\begin{array}{l}\text { Praça da } \\
\text { República }\end{array}$ & Centro (Parte), Gamboa, Santo Cristo e Saúde & 0,000 & 26 & $\begin{array}{c}\text { Todos os } \\
\text { Santos }\end{array}$ & $\begin{array}{l}\text { Água Santa, Engenho de Dentro, Lins de } \\
\text { Vasconcelos e Todos os Santos }\end{array}$ & $\mathrm{x}$ \\
\hline 5 & Mem de Sá & Centro (Parte), Lapa e Paquetá & $\mathrm{x}$ & 27 & $\begin{array}{l}\text { Vicente de } \\
\text { Carvalho }\end{array}$ & $\begin{array}{l}\text { Colégio (Parte), Irajá, Vicente de Carvalho, Vila } \\
\text { Kosmos, Vila da Penha e Vista Alegre }\end{array}$ & $\mathrm{x}$ \\
\hline 6 & Cidade Nova & $\begin{array}{l}\text { Catumbi, Cidade Nova, Estácio, Rio Comprido e } \\
\text { Centro (parte) }\end{array}$ & 0,389 & 28 & Campinho & $\begin{array}{c}\text { Campinho, Cascadura, Praça Seca, Quintino } \\
\text { Bocaiúva e Vila Valqueire }\end{array}$ & $\mathrm{x}$ \\
\hline 7 & Santa Teresa & Santa Teresa & 0,000 & 29 & Madureira & $\begin{array}{l}\text { Cavalcanti, Engenheiro Leal, Madureira, Turiaçu e } \\
\text { Vaz Lobo }\end{array}$ & $\mathrm{x}$ \\
\hline 9 & Catete & Catete, Cosme Velho, Flamengo, Glória e Laranjeiras & $x$ & 30 & $\begin{array}{l}\text { Marechal } \\
\text { Hermes }\end{array}$ & Bento Ribeiro, Marechal Hermes e Oswaldo Cruz & $\mathrm{x}$ \\
\hline 10 & Botafogo & Botafogo, Humaitá e Urca & 0,044 & 31 & $\begin{array}{l}\text { Ricardo de } \\
\text { Albuquerque }\end{array}$ & $\begin{array}{l}\text { Anchieta, Guadalupe, Parque Anchieta e Ricardo de } \\
\text { Albuquerque }\end{array}$ & $\mathrm{x}$ \\
\hline 12 & Copacabana & Copacabana (Parte) e Leme & 0,286 & 32 & Taquara & $\begin{array}{l}\text { Anil, Cidade de Deus, Curicica, Gardênia Azul, } \\
\text { Jacarepaguá e Taquara }\end{array}$ & $\mathrm{x}$ \\
\hline 13 & Ipanema & Copacabana (Parte) & 0,143 & 33 & Realengo & $\begin{array}{l}\text { Campo dos Afonsos, Deodoro, Jardim Sulacap, } \\
\text { Magalhăes Bastos, Realengo e Vila Miltar }\end{array}$ & $\mathrm{x}$ \\
\hline 14 & Leblon & Ipanema e Leblon & 0,047 & 34 & Bangu & Bangu, Gericinó, Padre Miguele Senador Camará & $\mathrm{x}$ \\
\hline 15 & Gávea & $\begin{array}{l}\text { Gávea, Jardim Botânico, Lagoa, São Conrado e } \\
\text { Vidigal + Rocinha }\end{array}$ & 0,091 & 35 & Campo Grande & $\begin{array}{l}\text { Campo Grande, Cosmos, Inhoaiba, Santíssimo e } \\
\text { Senador Vasconcelos }\end{array}$ & $\mathrm{x}$ \\
\hline $16+42$ & Barra da Tjuca & $\begin{array}{l}\text { Barra da Tijuca, Itanhangá, Joá + Recreio dos } \\
\text { Bandeirantes, Barra de Guaratiba, Camorim, } \\
\text { Grumari, Vargem Grande e Vargem Pequena }\end{array}$ & $\mathrm{x}$ & 36 & Santa Cruz & Paciência e Santa Cruz & $\mathrm{x}$ \\
\hline 17 & São Cristóvão & Caju, Mangueira, São Cristóvão e Vasco da Gama & 0,000 & 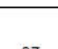 & Ulha do & $\begin{array}{l}\text { Bancários, Cacuia, Cidade Universitária, Cocotá, } \\
\text { Freguesia, Galeão, Jardim Carioca, Jardim }\end{array}$ & 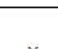 \\
\hline 18 & $\begin{array}{l}\text { Praça da } \\
\text { Bandeira }\end{array}$ & Maracanã, Praça da Bandeira e Tijuca (Parte) & 0,000 & 37 & Governador & $\begin{array}{l}\text { Guanabara, Moneró, Pitangueiras, Portuguesa, Praia } \\
\text { da Bandeira, Ribeira, Tauá e Zumbi }\end{array}$ & $x$ \\
\hline 19 & Tijuca & Alto da Boa Vista e Tijuca (Parte) & $\mathrm{x}$ & 38 & Irajá & $\begin{array}{l}\text { Brás de Pina (Parte), Cordovil, Jardim América, } \\
\text { Parada de Lucas, Penha Circular (Parte) e Vigário }\end{array}$ & $\mathrm{x}$ \\
\hline 20 & Vila Isabel & Andarai, Grajaú e Vila Isabel & $\mathrm{x}$ & 39 & Pavuna & $\begin{array}{c}\text { Acari, Barros Filho, Costa Barros, Parque Colúmbia } \\
\text { e Pavuna }\end{array}$ & $\mathrm{x}$ \\
\hline 21 & Bonsucesso & $\begin{array}{c}\text { Benfica, Bonsucesso, Higienópolis, Manguinhos, } \\
\text { Maré e Ramos }\end{array}$ & 0,000 & 40 & Honório Gurgel & $\begin{array}{l}\text { Coelho Neto, Colégio (Parte), Honório Gurgel e } \\
\text { Rocha Miranda }\end{array}$ & $\mathrm{x}$ \\
\hline 22 & Penha & $\begin{array}{l}\text { Brás de Pina (Parte), Olaria, Penha e Penha Circular } \\
\text { (Parte) }\end{array}$ & 0,000 & 41 & Tanque & Freguesia (Jacarepaguá), Pechincha e Tanque & $\mathrm{x}$ \\
\hline 23 & Méier & Cachambi e Méier & 0,000 & 43 & Guaratiba & Guaratiba, Pedra de Guaratiba e Sepetiba & $\mathrm{x}$ \\
\hline 24 & Piedade & Abolição, Encantado, Piedade e Pilares & $\mathrm{x}$ & 44 & Inhaúma & $\begin{array}{l}\text { Del Castilho, Engenho da Rainha, Inhaúma, Maria da } \\
\text { Graça e Tomás Coelho }\end{array}$ & 0,000 \\
\hline
\end{tabular}

que deveria ter ocorrido na $20^{\text {a }}$ CISP caso a $1^{\text {a }}$ CIPP não tivesse sido implementada. Portanto, o efeito da $1^{\mathrm{a}}$ CIPP sobre a taxa de ocorrências é obtido a partir da diferença entre a queda observada na $20^{\mathrm{a}}$ CISP e aquela verificada no controle sintético. A Tabela 3 mostra que a $1^{\text {a }}$ CIPP implica em uma redução mais acentuada na taxa de ocorrências da $20^{\text {a }}$ CISP do que a observada no controle sintético. Por um lado, constata-se uma redução de 27 ocorrências por 100 mil habitantes na $20^{\text {a }}$ CISP. Por outro lado, verifica-se uma queda de 15 na taxa de ocorrências do controle sintético da $20^{\text {a }}$ CISP. Estes números sugerem que a política é consistente com diminuição relativa de aproximadamente $17 \%$ na taxa de ocorrências: $[-27-(-15)] / 70=-0,17=-17 \%)$ e, portanto, pode-se dizer que $o$ programa é bem sucedido em reduzir a criminalidade.

Para determinar a probabilidade de observar um efeito de magnitude parecida com o obtido para a $1^{\text {a }}$ CIPP, realiza-se a estimação do método de controle sintético para todas as unidades incluídas no conjunto de delegacias semelhantes. O objetivo é verificar, com que frequência variações de $17 \%$ ou mais podem ser observadas em delegacias não afetadas pelo programa. Os resultados deste procedimento são apresentados na Figura 6. Os gráficos contidos nesta Figura mostram que, na verdade, não é tão incomum encontrar efeitos de $17 \%$ ou mais. Dentre as 10 delegacias com melhor ajuste, para o período 
Tabela 3: Efeito da 1a CIPP

\begin{tabular}{lccc}
\hline \hline & 20a CISP & $\begin{array}{c}\text { Controle Sintético } \\
\text { da 20a CISP }\end{array}$ & $\begin{array}{c}\text { Diferença das } \\
\text { Diferenças }\end{array}$ \\
\cline { 2 - 4 } & $(1)$ & $(2)$ & $(3)$ \\
\hline $\begin{array}{l}\text { Taxa de ocorrências em fevereiro } \\
\text { de } 2015\end{array}$ & 70 & 67 & \\
$\begin{array}{l}\text { Taxa de ocorrências em ag osto } \\
\text { de 2015 }\end{array}$ & 43 & 52 & -12 \\
Diferença & -27 & -15 & \\
\hline \hline
\end{tabular}

Notas. Esta tabela fornece o ef eito da $1^{a}$ CIPP.

pré-intervenção, verifica-se que pelo menos 3 apresentam redução na taxa de ocorrência maior, ou semelhante, àquela verificada na $20^{\mathrm{a}} \mathrm{CISP}^{23}$.

\section{Conclusão}

Esse trabalho apresenta uma avaliação do impacto do projeto-piloto da primeira CIPP sobre os delitos monitorados pelo Sistema de Indicadores de Metas (SIM). Com o uso do método de controle sintético aponta-se para uma redução de $17 \%$ na taxa de ocorrências do SIM por 100.000 habitantes. Isso equivale a dizer que houve uma redução de aproximadamente 20 ocorrências na área da CIPP em relação às comparadas.

Entretanto, questiona-se o quão provável é um desempenho dessa magnitude. Analisadas outras dez delegacias com padrão de ocorrências no período pré-intervenção mais parecido com o da $20^{\mathrm{a} C I S P}$, verifica-se que pelo menos três apresentam redução maior ou semelhante. Portanto, é necessário ter cautela ao interpretar o efeito da $1^{\text {a }}$ CIPP quanto à redução de crimes, visto que o impacto estimado não é suficientemente grande para distingui-lo de casos em que nenhuma política específica foi implementada. Pode-se identificar também, como mostra a Figura 4, que os últimos meses considerados não tiveram resultados tão expressivos quanto maio e junho. Levanta-se a dúvida, consequentemente, da relação deste resultado com o possível esforço extra para cumprimento das metas estabelecidas para o primeiro semestre do ano, o que não pôde ser controlado no presente estudo.

Cabe frisar que esta avaliação mede apenas o efeito do projeto-piloto sobre a criminalidade. A redução desta é somente um dos objetivos da CIPP, que também pretende

\footnotetext{
${ }^{23}$ As três delegacias com redução maior, ou semelhante, àquela verificada na $20^{\mathrm{a}}$ CISP são: a $10^{\mathrm{a}}$ CISP (Botafogo), a $7^{\mathrm{a}}$ CISP (Santa Teresa) e a $22^{\mathrm{a}}$ CISP (Penha).
}

Econômica-Niterói, v. 19, n. 2, p. 87-110. dezembro, 2017 
Figura 6: Verificando a Probabilidade de Encontrar Efeitos de Magnitude Semelhante ao Observado para a $20^{\text {a }}$ CISP.

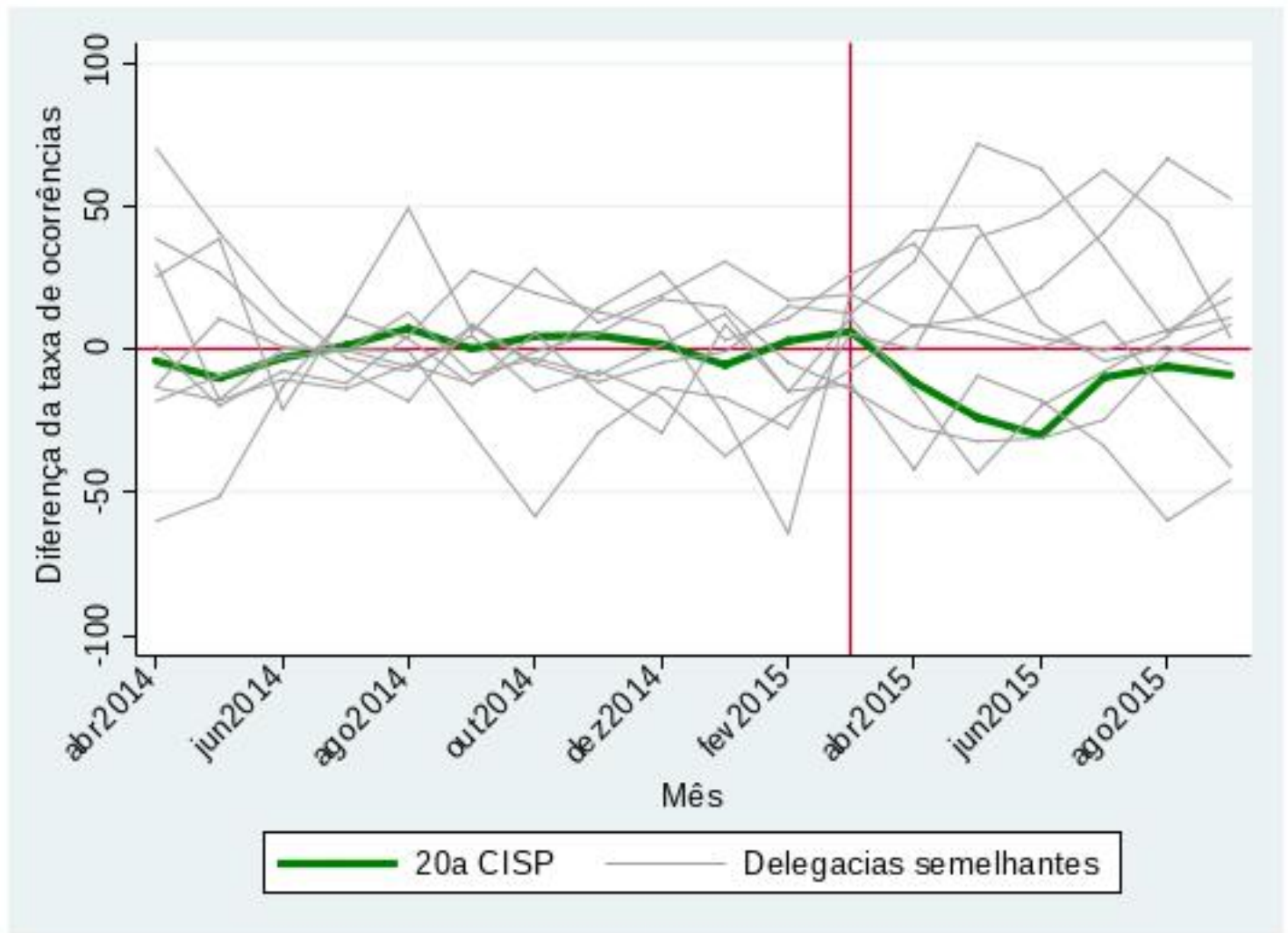

diminuir os desvios de conduta policial e aumentar a confiança mútua entre polícia e comunidade. Neste sentido a Secretaria de Segurança do Estado do Rio de Janeiro têm realizado não apenas o monitoramento dos indicadores de criminalidade, mas também coordenado reuniões envolvendo diversos agentes afetados pelo projeto. De maneira geral, observa-se que a falta de mecanismos institucionais regulamentados afeta atividades previstas para consecução dos princípios da CIPP, como, por exemplo, as ações integradas com a municipalidade ${ }^{24}$. Na ausência de processos de trabalho claros, os resultados tendem a ser muito dependentes da capacidade de liderança do Comandante da CIPP e do Comandante do BPM.

Por fim, ressaltam-se os resultados do projeto à luz do efetivo empregado. Como comentado, a $1^{\text {a }}$ CIPP, comparada com todos os BPM, está em $20^{\circ}$ lugar entre as 40 unidades (39 batalhões mais a CIPP) em termos de número de policiais por 100 mil habitantes. A razão de policiais está, portanto, na mediana dos outros batalhões. O que pode indicar que não houve um emprego intenso de recursos humanos no projeto, e, por outro lado, que a

\footnotetext{
${ }^{24}$ Esses regulamentos já estão sendo construídos em reuniões conjuntas com os atores responsáveis.
} 
companhia da área possuía, antes da CIPP, uma quantidade relativamente baixa quando comparada com as demais.

A comparação da CIPP com companhias da polícia militar com quantidades similares de efetivo permitiria a construção de um modelo estatístico mais adequado, o que não foi feito porque os dados referentes ao número de policiais por CISP não são divulgados. A impossibilidade desse teste mantém pertinente, assim, uma pergunta que perpassa as diversas tentativas de implantação de novos tipos de serviço policial: se os resultados alcançados são devido ao modelo policial específico e/ou ao incremento de mais policiais na região.

\begin{abstract}
This study presents an impact evaluation of the implementation of the Integrated Company of Proximity Policing (CIPP), a project carried out by the Rio de Janeiro State Police (PMERJ). Usinga synthetic control method, and a database from the Institute of Public Security of the State of Rio de Janeiro (ISP), we find that the CIPP reduces crimes in comparison with the control group. However, according to the adopted methodology, this reduction in crime due to CIPP implementation is not statistically different from the one observed in areas that were left out of the program.
\end{abstract}

Keywords: crime, proximity policing, synthetic control

JEL: K42,O38, O54

\title{
Referências bibliográficas
}

ABADIE, A.; DIAMOND, A.; HAINMUELLER, J. Synthetic control methods for comparative case studies: Estimating the effect of california's tobacco control program. Journal of the American statistical Association, Taylor \& Francis, v. 105, n. 490, p. 493-505, 2010.

ABADIE, A.; GARDEAZABAL, J. The economic costs of conflict: A case study of the basque country. American economic review, v. 93, n. 1, p. 113-132, 2003.

ALBERNAZ, E. R.; CARUSO, H.; PATRÍCIO, L. Tensões e desafios de um policiamento comunitário em favelas do rio de janeiro. São Paulo em Perspectiva, v. 21, n. 2, p. 39-52, 2007.

BECKER, G. S. Crime and punishment: An economic approach. In: The economic dimensions of crime. [S.1.]: Springer, 1968. p. 13-68.

Econômica-Niterói, v. 19, n. 2, p. 87-110. dezembro, 2017 
CANO, I.; BORGES, D.; RIBEIRO, E. Os donos do morro: uma avaliação exploratória do impacto das unidades de polícia pacificadora (upps) no rio de janeiro. 2012.

FAJNZYLBER, P.; LEDERMAN, D.; LOAYZA, N. Inequality and violent crime. The journal of Law and Economics, The University of Chicago Press, v. 45, n. 1, p. 1-39, 2002.

FERREIRA, F. M. M. O policiamento de proximidade: O caso especial do programa"comércio seguro"da baixa da cidade do porto. 2014.

GROGGER, J. Market wages and youth crime. Journal of labor Economics, The University of Chicago Press, v. 16, n. 4, p. 756-791, 1998.

HENRIQUES, R.; RAMOS, S. Upp social: ações sociais para a consolidação da pacificação. Rio: a hora da virada. Rio de Janeiro: Campus/Elsevier, p. 242-254, 2011.

JUNIOR, J. Da favela para o mundo: a história do grupo cultural Afro Reggae. [S.1.]: Ediouro Publicações, 2006.

KELLY, M. Inequality and crime. Review of economics and Statistics, MIT Press, v. 82, n. 4, p. 530-539, 2000.

LOCHNER, L.; MORETTI, E. The effect of education on crime: Evidence from prison inmates, arrests, and self-reports. American economic review, v. 94, n. 1, p. 155-189, 2004.

PAZ, F. I. para la. Evaluacion del impacto del plan nacional de vigilancia comunitaria por cuadrantes. Serie Informes, v. 18, 2012.

PNC. Estrategia institucional para la seguridad ciudadana: Plan nacional de vigilancia comunitaria por cuadrantes (pnvcc). Bogotá, 2010. Acesso em 06 fev. 2017. Disponível em: <http://www.oas.org/es/sap/dgpe/innovacion/banco/anexoll\%20i. I1\%20pnvcc.pdf>.

PNUD. Coletânea convivência e segurança cidadã: guias de gestão territorial participativa. Brasília: PNUD, 2013.

RIO DE JANEIRO (Estado). Instrução normativa pmerj/emg. Rio de Janeiro, n. 22, 2015.

ROLIM, M. A síndrome da rainha vermelha: policiamento e segurança pública no século XXI. [S.1.]: Zahar, 2006.

SOARES, B. et al. O que pensam os policiais. Revista Ciência Hoje, v. 49, n. 294, p. 34-39, 2012.

VASCO, J. Polícia de Proximidade. Dissertação (B.S. thesis) — [sn], 2014. 
VAZ, B. O. E. Três Ensaios em Microeconometria sobre Crime, Política e Migração. Tese (Doutorado) — PUC-Rio, 2014.

WAQUIM, B. Prevenção situacional: Teses, técnicas e reflexões. Âmbito Jurídico, Rio Grande, XII, v. 67, 2009. Acesso em set 2015. Disponível em: <http: //www.ambito-juridico.com.br/site/index.php?n\_link=revistal_artigos $\_l e i t u r a l \& a r t i g o l$ id $=6544>$.

Recebido em 7 de fevereiro de 2017. Aceito para publicação em 9 de março de 2018. 
ANEXO

Figura 1A: Mapa da Cidade do Rio de Janeiro (Capital do Estado)Contendo aDelimitação Geográfica de cadaCISP

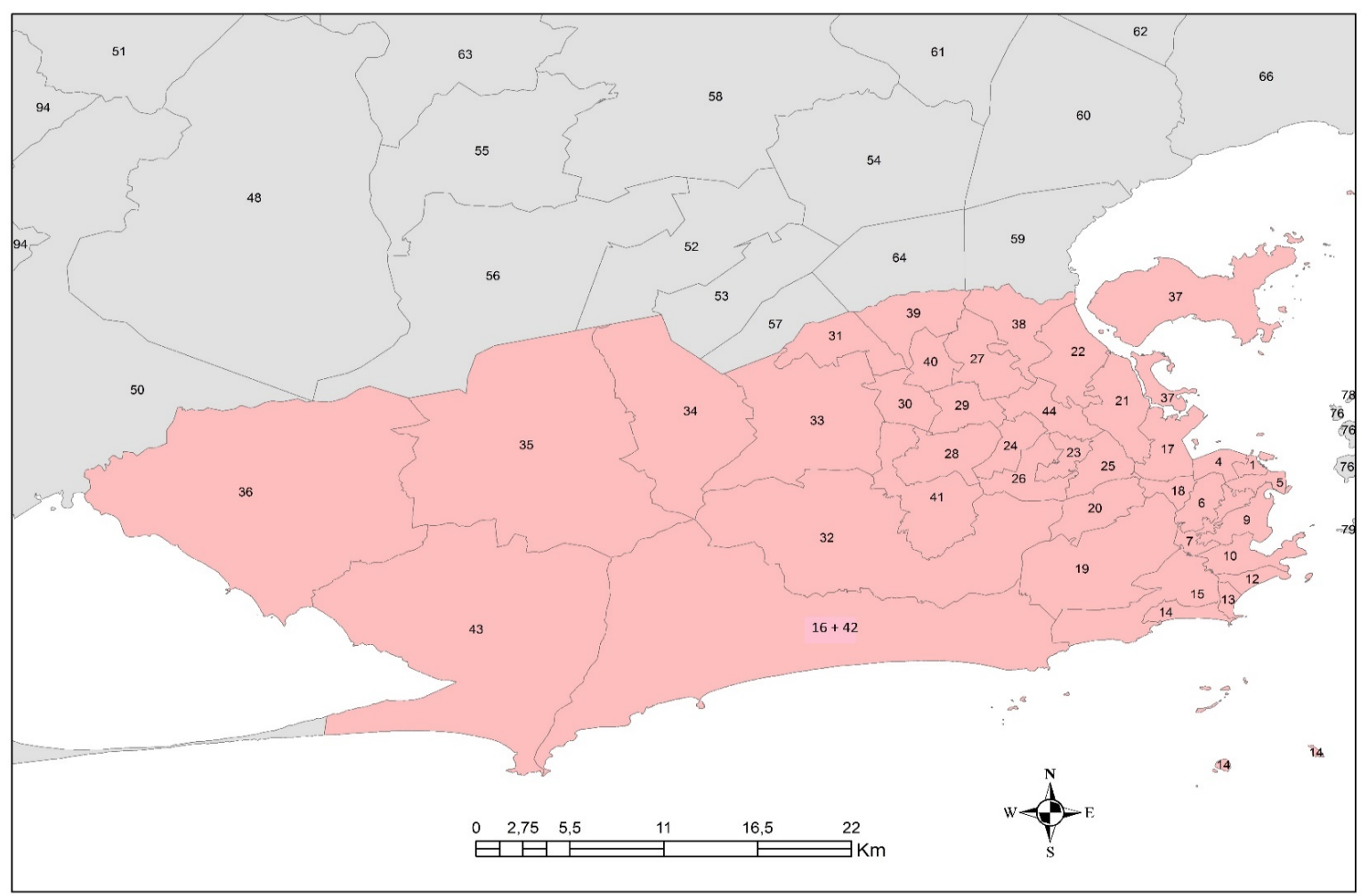


Tabela 1A: Relaçãodas CISP da Capital (Contendo Informação Sobre o Bairro da Sede e uma Lista de Bairros Cobertos)

\begin{tabular}{|c|c|c|c|c|c|}
\hline CISP & Bairro da Sede & Bairros na Área de Cobertura & CISP & Bairro da Sede & Bairros na Área de Cobertura \\
\hline 1 & Praça Mauá & Centro (Parte) & 25 & Engenho Novo & $\begin{array}{l}\text { Engenho Novo, Jacaré, Jacarezinho, Riachuelo, Rocha, } \\
\text { Sampaio e Săo Francisco Xavier }\end{array}$ \\
\hline 4 & Praça da República & Centro (Parte), Gamboa, Santo Cristo e Saúde & 26 & Todos os Santos & $\begin{array}{l}\text { Agua Santa, Engenho de Dentro, Lins de Vasconcelos e } \\
\text { Todos os Santos }\end{array}$ \\
\hline 5 & Mem de Sá & Centro (Parte), Lapa e Paquetá & 27 & $\begin{array}{c}\text { Vicente de } \\
\text { Carvalho }\end{array}$ & $\begin{array}{l}\text { Colégio (Parte), Irajá, Vicente de Carvalho, Vila Kosmos, } \\
\text { Vila da Penha e Vista Alegre }\end{array}$ \\
\hline 6 & Cidade Nova & $\begin{array}{l}\text { Catumbi, Cidade Nova, Estácio, Rio Comprido e Centro } \\
\text { (parte) }\end{array}$ & 28 & Campinho & $\begin{array}{l}\text { Campinho, Cascadura, Praça Seca, Quintino Bocaiúva e } \\
\text { Vila Valqueire }\end{array}$ \\
\hline 7 & Santa Teresa & Santa Teresa & 29 & Madureira & $\begin{array}{l}\text { Cavalcanti, Engenheiro Leal, Madureira, Turiaçu e Vaz } \\
\text { Lobo }\end{array}$ \\
\hline 9 & Catete & Catete, Cosme Velho, Flamengo, Glória e Laranjeiras & 30 & Marechal Hermes & Bento Ribeiro, Marechal Hermes e Oswaldo Cruz \\
\hline 10 & Botafogo & Botafogo, Humaitá e Urca & 31 & $\begin{array}{l}\text { Ricardo de } \\
\text { Albuquerque }\end{array}$ & $\begin{array}{l}\text { Anchieta, Guadalupe, Parque Anchieta e Ricardo de } \\
\text { Albuquerque }\end{array}$ \\
\hline 12 & Copacabana & Copacabana (Parte) e Leme & 32 & Taquara & $\begin{array}{l}\text { Anil, Cidade de Deus, Curicica, Gardênia Azul, } \\
\text { Jacarepaguá e Taquara }\end{array}$ \\
\hline 13 & Ipanema & Copacabana (Parte) & 33 & Realengo & $\begin{array}{l}\text { Campo dos Afonsos, Deodoro, Jardim Sulacap, } \\
\text { Magalhäes Bastos, Realengo e Vila Miltar }\end{array}$ \\
\hline 14 & Leblon & Ipanema e Leblon & 34 & Bangu & Bangu, Gericinó, Padre Miguel e Senador Camará \\
\hline 15 & Gávea & $\begin{array}{l}\text { Gávea, Jardim Botânico, Lagoa, Såo Conrado e Vidigal + } \\
\text { Rocinha }\end{array}$ & 35 & Campo Grande & $\begin{array}{l}\text { Campo Grande, Cosmos, Inhoaiba, Santissimo e Senador } \\
\text { Vasconcelos }\end{array}$ \\
\hline $16+42$ & Barra da Tijuca & $\begin{array}{c}\text { Barra da Tjuca, ttanhangá, Joá + Recreio dos } \\
\text { Bandeirantes, Barra de Guaratiba, Camorim, Grumari, } \\
\text { Vargem Grande e Vargem Pequena }\end{array}$ & 36 & Santa Cruz & Paciência e Santa Cruz \\
\hline 17 & São Cristóvão & Caju, Mangueira, São Cristóvão e Vasco da Gama & 37 & tha do Governador & $\begin{array}{l}\text { Bancários, Cacuia, Cidade Universitária, Cocotá, } \\
\text { Freguesia, Galeâa, Jardim Carioca, Jardim Guanabara, }\end{array}$ \\
\hline 18 & Praça da Bandeira & Maracanã, Praça da Bandeira e Tijuca (Parte) & & mita tor & $\begin{array}{c}\text { Moneró, Pitangueiras, Portuguesa, Praia da Bandeira, } \\
\text { Riberia, Tauá e Zumbi }\end{array}$ \\
\hline 19 & Tijuca & Alto da Boa Vista e Tijuca (Parte) & 38 & Irajá & $\begin{array}{l}\text { Brás de Pina (Parte), Cordovil, Jardim América, Parada de } \\
\text { Lucas, Penha Circular (Parte) e Vigário Geral }\end{array}$ \\
\hline 20 & Vila Isabel & Andarai, Grajaú e Vila Isabel & 39 & Pavuna & $\begin{array}{l}\text { Acari, Barros Filho, Costa Barros, Parque Colúmbia e } \\
\text { Pavuna }\end{array}$ \\
\hline 21 & Bonsucesso & $\begin{array}{c}\text { Benfica, Bonsucesso, Higienópolis, Manquinhos, Maré e } \\
\text { Ramos }\end{array}$ & 40 & Honório Gurgel & $\begin{array}{l}\text { Coellho Neto, Colégio (Parte), Honório Gurgel e Rocha } \\
\text { Miranda }\end{array}$ \\
\hline 22 & Penha & $\begin{array}{l}\text { Brás de Pina (Parte), Olaria, Penha e Penha Circular } \\
\text { (Parte) }\end{array}$ & 41 & Tanque & Freguesia (Jacarepaguá), Pechincha e Tanque \\
\hline 23 & Méier & Cachambie Méier & 43 & Guaratiba & Guaratiba, Pedra de Guaratiba e Sepetiba \\
\hline 24 & Piedade & Abolição, Encantado, Piedade e Pilares & 44 & Inhaúma & $\begin{array}{l}\text { Del Castilho, Engenho da Rainha, Inhaúma, Maria da } \\
\text { Graça e Tomás Coelho }\end{array}$ \\
\hline
\end{tabular}

